\title{
O PEDÁGIO NO PARANÁ: LEI PERMISSIVA E CONTRATO FORTE
}

THE ROAD TOLL IN PARANÁ STATE: PERMISSIVE LAW AND STRONG CONTRACT

Irineu Mario Colombo ${ }^{1}$

\section{RESUMO}

Este artigo apresenta a ambientação política que impulsionou a aprovação de um Projeto de Lei na Assembleia Legislativa do Paraná, pelo governo paranaense no ano de 1995, que resultou na concessão à iniciativa privada dos principais trechos de rodovias no Paraná. Aponta para os detalhes da tramitação, das votações, dos encaminhamentos e avalia o mérito da proposta, analisando a conjuntura em que foi votada, sob a hegemonia do pensamento neoliberal, e suas consequências para os usuários das rodovias paranaenses pedagiadas. Apresenta-se, ainda, uma avaliação técnica e política do tema pedágio até 2015 e compara o caso do Paraná com os leilões de pedágios nas rodovias federais, concluindo que a lei foi permissiva e o contrato com as empresas foi muito seguro juridicamente. Pautando-se para tal pesquisa no viés analítico-comparativo.

PALAVRAS-CHAVE: Pedágio. Neoliberalismo. Lei Complementar. Concessão.

\section{ABSTRACT}

This article presents the policy that boosted the approval of a law in the Legislative Assembly of Paraná, by the government in 1995, which resulted in the concession to the private sector the main stretches of highway in Parana. Points to the details of the voting procedure, debate and assesses the merits of the proposal, at the same time analyzing the situation in which it was approved, under the hegemony of neoliberal thought, and significances for road users. It also presents a technical and political evaluation of the topic toll up to 2015 and compares the case of Paraná with the toll auctions on federal highways, concluding that the law was permissive and the contract with the companies was very legally secure. Referring to such research in the comparative-analytical bias.

KEYWORDS: Road toll. Neoliberalism. Complementary Law. Concession.

JEL Classification: D72; K12; K20.

\footnotetext{
1 Professor do IFPR. Licenciado em História (FAFI-Palmas), Especialista em História Econômica (FAFI-Patrocínio), Mestre em Educação (UFPR) e Doutor em História Social (UnB). E-mail: colombo@ifpr.edu.br
} 


\section{INTRODUÇÃO}

O pedágio implantado nas rodovias do Paraná pelo governo estadual pode ser considerado um dos mais caros do mundo e os serviços, prestados pelas concessionárias, sofrem constantes reclamações dos usuários, conforme verificado a partir da análise de fontes jornalísticas como, por exemplo, o jornal Paraná Online Tribuna (2007) em que foram apresentados dados de uma pesquisa realizada com a intensão de medir a satisfação dos usuários das rodovias pedagiadas no Paraná, onde se constata que: "71\% dos usuários consideram o valor do pedágio incompatível com a qualidade das estradas e $15 \%$ acreditam que o valor pago é justo".

Destaca ainda que, "78,3\% querem que o governo negocie um novo modelo de contrato no Paraná e outros $13 \%$ acham prudente que o Estado espere o fim da vigência do atual contrato: 2021".

Outra fonte, a Revista Congresso em Foco (2015) destaca que o "Pedágio no Brasil está entre os mais caros do mundo" e a FENASDETRAN (2015) declara que o "Paraná tem o pedágio mais caro do mundo". Com isso ocorreram inúmeras ações judiciais, bem como, "a concessão de rodovias à iniciativa privada no Paraná desencadeou uma série de protestos e questionamentos, em especial, quanto aos valores das tarifas cobradas" (FIGUEIREDO, 2003, p. 51).

Infere-se, a partir destes dados que os valores cobrados pelos serviços prestados desagradam a maioria dos usuários, que esperam dos governantes uma atitude que promova a redução nas tarifas, antes mesmo do término do contrato.

Poucos usuários têm conhecimento em que circunstâncias a lei dos pedágios foi aprovada no Paraná. Portanto, se faz necessária uma retomada história do processo de tramitação desta lei até sua aprovação e aplicação de fato. O recorte temporal deste estudo é o período de 1995 a 2015, observando os aspectos econômicos e políticos envolvidos. A escolha deste recorte se deve a dois fatores: 1) em 2007 o Governo Federal inicia um novo processo de leilões que permite comparações entre os modelos adotados; 2) até 2015, trocaram os governantes e várias ações administrativas e jurídicas foram tomadas. Combinando estes dois aspectos, mais a distância de tempo recomendada para a análise e a crescente bibliografia revisitada, permitiu ao historiador econômico conclusões que o frescor do momento não possibilitaria.

O modelo de pedagiamento adotado no Paraná foi um dos primeiros implantado no Brasil. Ao compará-lo com outros modelos de leilões posteriormente realizados, por exemplo, pelo Governo Federal, percebe-se o preço político pago pelo governo paranaense da época, ao apressar a aprovação de uma Lei de Concessões. As críticas tratam dos benefícios às empresas vencedoras do leilão, com contratos inflexíveis, pesando sobre a economia estadual e, consequentemente ao usuário.

Diante disso, fica evidente a necessidade de uma análise do contexto político em que esta lei foi aprovada no Paraná, bem como avaliar seus efeitos práticos, econômicos com as concessões mais tardias.

Então, partindo destas inquirições o presente artigo analisará: Que fatores políticos e econômicos levaram o Paraná a ser vanguarda nesse tipo de concessão? Quais critérios adotados para a concessão são os mais questionados ou refutados? Para que a partir das análises avaliar os critérios, comparar valores e serviços, de maneira ampla, consequente à aprovação precoce da respectiva legislação.

O lapso temporal necessário, permite declarar a atualidade deste artigo, justifica seu aparente retardo em relação aos fatos estudados e explica a suposta 
extemporaneidade; porquanto que não cabe ao pesquisador reconstruir a realidade, mas buscar sua essência como existência conjuntural ou estrutural.

Concordamos com o historiador Philippe Ariès que tem a convicção de que é o historiador que dá existência a uma realidade e que é necessário o afastamento dela para tomar consciência das anomalias ao percebê-las na sucessão dos fenômenos (ARIÈS, 1989, p. 167). E também da sua percepção informativa de que o interesse contemporâneo pelos fenômenos econômicos e sociais revelam o interesse da historiografia pelos fatos existenciais, mais próximos da vida cotidiana das pessoas. "Mas eles [os fatos existenciais] não possuem esta qualidade existencial por si mesmos. Se são isolados, tornam-se como fatos políticos, fatos abstratos que perderam seu sentido e sua cor. Eles existem em sua estrutura" (ARIĖS, 1989, p. 171).

Por isso, a escolha metodológica, em que o lapso temporal se torna luneta que permite a reflexão hodierna dentro da história econômica e da economia política, para entender a conjuntura em que e como se deu a implantação do pedagiamento nas principais rodovias do Paraná.

Este artigo estrutura-se em quatro tópicos. No primeiro, apresentamos a ambientação política da aprovação da lei de concessões na Assembleia Legislativa do Estado e suas características, entre as principais, está a delegação de compromissos entre as empresas e o Estado, remetidos a letra do contrato; No segundo tópico, abordamos a polêmica das altas tarifas, principal aspecto combatido política, administrativa e judicialmente; No terceiro, ilustramos a rigidez jurídica apresentado pelos contratos em favor das concessionárias e por fim, a conclusão deste artigo.

\section{A LEI COMPLEMENTAR 76/1995 NO CONTEXTO NEOLIBERAL}

No começo de dezembro de 1995 inicia a tramitação, na Assembleia Legislativa do Paraná, do Projeto de Lei no. 20/1995 que tratava das concessões e permissões públicas, com o fim de complementar a Constituição Estadual. A proposta tratava de permissões e concessões de vários tipos de serviços e obras. As bancadas oposicionistas fizeram emendas, que foram todas rejeitadas, e na primeira votação, os líderes do PMDB e do PT votaram contra. Contudo, no dia 21 de dezembro, praticamente às vésperas do Natal, na segunda e última votação, com alguns deputados viajando, outros ausentes em plenário, a lei foi aprovada. Foram manifestados apenas três votos contrários.

Os deputados que rejeitaram a proposta foram considerados, pelo restante do plenário, como antiquados e não sintonizados com as necessidades de um Estado que precisava se modernizar. Entre os argumentos retóricos destes oposicionistas, estava a defesa dos interesses da sociedade. Aquele projeto de lei, que parecia despretensioso, tornou-se um grande problema político frente aos paranaenses, pois permitiu a cobrança do pedágio com tarifa alta, sem opções de revisão, repactuação ou extinção.

O texto do Projeto de Lei foi aprovado dentro de um contexto histórico em que o pensamento neoliberal destacava as privatizações, como meio de garantir ao Estado a contenção de gastos necessária para sua recuperação econômica, e consequente melhoria em sua infraestrutura sucateada. Obedecia também 
[...] aos ditames da orientação política do Governo Federal de conceder os serviços de infraestrutura à iniciativa privada, no intuito de elevar os níveis de investimento, modernização institucional e desconcentração administrativa (FIGUEIREDO, 2003, p. 48).

Tal Projeto de Lei foi sancionado no mesmo dia de sua aprovação pelo governador Jaime Lerner do PSDB (gestão 1995-1998) como Lei Complementar $\mathrm{n}^{\circ}$ 76/95 (PARANÁ, 1995). A Lei disciplinava as concessões e permissões de serviços públicos no Paraná em termos genéricos, mas embutia ali, um estratagema que possibilitava garantida remuneração ao pedagiamento das principais rodovias estaduais.

A tática de aprovar de forma rápida, no final do ano, impondo um discurso de solução moderna, sem o necessário debate e aperfeiçoamento da lei, foi um dos fatores que, aparentemente, trouxe prejuízos à economia dos paranaenses.

O planejamento feito pelo governo do Paraná para implementação do Programa de Concessão de Rodovias teve a duração de seis meses. O que pode explicar grande parte dos equívocos cometidos ao longo do processo de implementação das concessões (KARAM; SHIMA, 2007, p. 122).

Além disso, a longa duração do contrato firmado entre o Estado e o setor privado deu ótimo retorno e segurança, a partir das cláusulas contratuais, aos interesses das empresas concessionárias.

O que se percebe de concreto é que no início do Governo Lerner (1995-1998), um arcabouço legal foi planejado para dar suporte à onda neoliberal que emanava do governo federal. Pautou-se a concessão das estradas para a iniciativa privada, como uma das ações de inovação dentro desta perspectiva. O que permite a seguinte indagação: Como esta opção política se estabeleceu como ideologia e lógica de ação de Estado?

A onda neoliberal se deu por meio do "processo de globalização" e do "Consenso de Washington". Com a globalização "muitas evidências foram levantadas para que as lideranças políticas do Brasil pactuassem com os atores e grupos hegemônicos da sociedade brasileira, a fim de incorporarem as reformas por ela veiculadas, dentre elas, a privatização dos setores de infraestrutura" (LEME, 2010, p. 134, grifo nosso). O "Consenso de Washington" foi uma "orientação políticoeconômica dominante na década de 1990 para os países em desenvolvimento, dentre eles, o Brasil, que apresentou relativo destaque na incorporação e implementação das reformas sugeridas pelo referido consenso" (LEME, 2010, p. 134).

No ano de 1989, foi convocada uma reunião em Washington (EUA) "pelo Institute for International Economics, entidade de caráter privado, com diversos economistas latino-americanos de perfil liberal", sendo que "John Willianson, economista inglês e diretor do instituto promotor do encontro, foi quem alinhavou os dez pontos tidos como consensuais entre os participantes" (NEGRÃO, 1996, p. 4). Entre os pontos de comum acordo estava a privatização de serviços e de empresas estatais.

Naquele período, a privatização era apresentada pela imprensa como algo desejável e bom pela natureza do esforço de iniciativas e da livre concorrência. "Tudo que é privado é bom", era um slogan muito usado para convencer e criar o senso comum de que a qualidade dos serviços privados era superior a qualidade dos serviços estatais e que, consequentemente, o desenvolvimento do país se daria a 
partir das privatizações. As concessões de rodovias tenderam a reorganizar e reavaliar as funções do Estado e

[...] o discurso utilizado para operar a mudança institucional em favor da desregulamentação, para em seguida criar um novo ambiente regulatório, buscou no ataque à burocracia, o apoio para tal empreitada (FIGUEIREDO, 2003, p. 48).

Por outro lado, a iniciativa privada exigia segurança jurídica e contratos bem formatados, sob robusta proteção legal, para fazer seus investimentos, e também buscavam margens seguras em relação a tarifação e prazos para os investimentos na melhoria da malha viária.

Apesar das dúvidas, da falta de marcos regulatórios e não experiência com agências reguladoras, o governo estadual apressou a votação. Adverte FIGUEIREDO (2003, p. 51) que se houvesse ao menos agência reguladora estaria "resguardando, ao menos em parte, o interesse público". Contudo, o contexto político era favorável à aprovação da Lei, pois se vivia num momento de governos neoliberais exaltados pela opinião pública (ou publicada) e pela imprensa. Nada mais adequado para propor uma lei como esta, para dar suporte a futuros contratos.

O governo estadual preparou e colocou nas mãos de um deputado aliado o projeto de lei, que, por sua vez, o defendeu com os mesmos argumentos do Consenso de Washington. O projeto foi aprovado e deu base e segurança nos contratos das rodovias pedagiadas no Paraná. A sutileza da lei, suas amarras e a maneira como foi aprovada, incorporou abonação jurídica às empresas vencedoras dos leilões. Tanto que, atualmente, a justiça e o poder executivo não conseguem fazer a revisão de valores, das metas ou propor alteração dos índices de reajuste.

Uma Lei Complementar, como é o caso da lei de pedágios do Paraná, tem a força de uma norma que só perde em status para a Constituição. A lei Complementar tem como propósito completar, explicar, adicionar algo à Constituição. Este tipo de lei se diferencia da ordinária pelo quórum exigido para sua aprovação. A lei ordinária exige apenas maioria simples de votos para ser aceita, já a Lei Complementar requer maioria absoluta e deve ter o seu âmbito material predeterminado pelo constituinte, ou seja, quem originou a Carta Magna solicitou uma lei a fim de complementar aquele tema (BRASIL, 2004, p. 368).

Perbelini (2008, p. 186), ao discutir a questão dos pedágios no Paraná, faz críticas afirmando que:

[...] as concessões paranaenses foram precedidas de um arcabouço jurídico, que possibilitou a implementação do programa de concessões do Estado. No entanto, não se contemplou um marco regulatório que servisse de regulação para o referido programa de concessão, a não ser uma mera fiscalização [...].

A Lei Complementar $n^{0} 76 / 1995$, traz logo no Art. 1, no inciso II de seu parágrafo único uma diretriz: concessão ou permissão em "vias estaduais, precedidas ou não de obras públicas". Aí começa a polêmica. A lei, por óbvio, devia tratar de todo tipo de concessão, não só de pedágio, mas este inciso não excetua ninguém, portanto, o pedágio poderia ser cobrado, mesmo sem obras, sem duplicações ou concertos.

Seu artigo $9^{\circ}$ destaca ainda que "os contratos poderão prever mecanismos de reajuste e revisão das tarifas, a fim de manter-se o equilíbrio econômico-financeiro". Deixa explícito que as concessionárias teriam o direito de aplicar o reajuste que 
considerassem necessário aos seus interesses, pois seriam elas mesmas as determinadoras de suas receitas e despesas, sem incluir os interesses dos usuários neste balanço econômico-financeiro

O mais sensato seria que os interesses dos cidadãos prevalecessem ou, ao menos, que fossem considerados em face dos interesses da iniciativa privada durante a elaboração daquela Lei, contudo, diante de um cenário onde os ideais neoliberais eram supremos, não restou dúvidas que o foco era atrair empresas ao leilão.

Por um lado, quem preparou a minuta da lei, previu um contrato com lucros e custos permanentes para as concessionárias e de outro lado, quem pagaria teria uma única opção para usar a rodovia: pagar, pois do contrário, não usaria. Não teria alternativa, ou se ajustaria ao elaborado plano de equilíbrio econômico-financeiro da iniciativa privada ou não poderia trafegar pelas rodovias pedagiadas.

Dentre os valores necessários para manter este equilíbrio, as concessionárias trabalhavam com a seguinte fórmula: tomariam dinheiro emprestado para todo o empreendimento; calculariam seu custo, e, manteriam tal despesa pari passu com renda para pagarem este custo. Se a empresa lucrasse mais, o que possibilitaria amortizar, recontratar custos, ou quitar dívida, não teria previsão contratual para seu equilíbrio econômico-financeiro beneficiar o usuário, ou seja, não haveria a necessidade de reduzir as tarifas mesmo que os lucros superassem as expectativas.

Em seu artigo 24 e seguintes, que tratam do contrato, destaca-se o direito das concessionárias reajustarem e reverem as tarifas, com relação à modernização dos serviços e outras tarefas a serem ajustadas. Contudo, isto remete para outros artigos que trata de assegurar o equilíbrio econômico-financeiro da concessionária, e este, está ligado ao artigo 28 que inclui os custos de financiamento e taxas para este equilíbrio.

Vários artigos da proposta tratam dos direitos dos usuários, mas o contrato fica intangível, pois caso se modernize com obras e serviços, implica-se no necessário equilíbrio econômico-financeiro e este está em relação aos custos operacionais bancários contratados, aceito aprioristicamente na lei como fato contratado.

O contrato poderá perdura por até 25 anos, conforme a redação dada pelo parágrafo $2^{\circ}$. do artigo 24 que declara "não poderá ser superior" a este período. A necessidade do equilíbrio econômico-financeiro passou a sobrepujar qualquer outra alegação legal, por mais que destacasse conceitos como: fiscalização, penalidades, publicação, direito de o usuário formar comitê de acompanhamento, entre outros. No espaço de tempo de até 25 anos, toda modernização de obras e serviços exigidos na concessão, bem como os custos do dinheiro financiado para tal, seria considerado para o ajuste tarifário.

O artigo 29, inciso IV, destaca que seria possível "extinguir a concessão, nos casos previstos nesta lei e na forma prevista no contrato", sendo que a lei não aborda claramente em quais casos, e se assim o fizesse, a forma (de que maneira, quando, as etapas, e outros procedimentos para esta extinção) estaria no contrato. Portanto, o segredo é o contrato, pois ali, mesmo que não cumpra integralmente a lei, dará os benefícios da broma - com o tempo e de uma maneira que permitiria a chicana.

Prosseguindo a análise, constata-se que o artigo 32 e seguintes, trata das possibilidades de intervenção pelo Estado. Neste caso, estando tudo nos termos contratados - que beneficia preferencialmente as concessionárias - em nada elas vacilariam que permitisse a cessação de seus lucros. 
Embora a Lei analisada neste artigo, assim como a Constituição Federal, trate do princípio da economicidade ${ }^{2}$ como um dos guias da contratação e trate também da modicidade das tarifas, em seu artigo 38 em nenhum momento trata do rompimento do contrato pela não observância deste princípio da economicidade e nem trata a forma de observá-lo em nenhum outro artigo. Portanto, ser módico e plausível para a economia popular, não passaria de mera declaração.

No último capítulo, "das disposições finais", destaca-se no artigo 41 que "fica o Estado autorizado a cobrar pedágio pela utilização de vias estaduais conservadas ou vias federais delegadas". Depois de todos os critérios necessários colocados na lei, viria esta derradeira sutileza, que fazia parte já do entendimento nacional sobre o processo de privatização, tendo o Paraná como avant première do neoliberalismo. A licitação dos trechos após esta lei "serviram de base para implantação do Programa de Concessões de Rodovias Federais" (FIGUEIREDO, 2003, p. 49), por isso, o entendimento entre os dois governos para que a lei paranaense já poderia prever delegação vindouras de trechos federais.

Deste modo, "[...] cabe chamar a atenção para o fato de que as concessões rodoviárias, no Estado do Paraná, terem sido precedidas da delegação, por parte do governo federal ao governo do Paraná, através de convênio firmado entre o Ministério dos Transportes e o Estado do Paraná, em outubro de 1996" (PERBELINI; ARAÚJO, 2008, p. 186). Onde as etapas foram: a Lei de 1995, a delegação federal em 1996 e o leilão em 1997.

As rodovias seriam delegadas pelo governo federal, e a boa vontade do governo estadual e o entendimento com as futuras concessionárias, promoveu este preparativo legal para tal. E estavam na onda, dentro da conjuntura que recomendava dar segurança contratual ao privatizar.

Este passou a ser um dos propósitos da forma de redação da lei: fazer um arcabouço para garantir a petrificação do contrato. Não importando tanto a Lei em si, mas sim o contrato. A segurança contratual, mesmo com a polêmica instalada, seria um dos pilares do novo liberalismo.

A questão privatista a qualquer modo, que estava em voga com uma ditadura retórica que constrangiam pessoas comuns ou até parlamentares que contestassem uma privatização, começou no governo Fernando Afonso Collor de Mello, quando fez do congresso um "bonapartismo aventureiro"3, com raízes bem fincadas no neoliberalismo, que, por conseguinte Fernando Henrique Cardoso (FHC) deu prosseguimento em oito anos de mandato. O ideário neoliberal, presente naquele governo, foi mostrado logo no seu discurso de posse, em que disse que executaria o programa econômico de Collor sem o seu aventureirismo político, num sentido mais romântico progressista.

Com o desejo de implantar o "modelo socioeconômico neoliberal, em consonância com a onda ideológica no mundo ocidental" o governo FHC apresentou em 1995 ao Congresso Nacional uma proposta legislativa com o argumento de "reforma do aparelho do Estado" (PARADELA, 1998, p. 77). Entre os aspectos apresentados, estava a redução da máquina do Estado por meio de privatizações.

\footnotetext{
${ }^{2} \mathrm{~A}$ economicidade é um dos princípios que norteiam os contratos administrativos. Tem relação com a concepção de menor custo, ou seja, da modicidade da tarifa - correspondente ao menor custo possível para a oferta adequada do serviço - desde que condizente com os parâmetros estabelecidos de qualidade.

3 Termo utilizado pelo sociólogo Ricardo Antunes, que atribuía ao governo Collor um traço bonapartista com alta dose de aventureirismo (ANTUNES, 2004).
} 
Um dos objetivos do "Consenso de Washington" é derivar nos países em desenvolvimento "a cópia de modelos administrativos de países desenvolvidos" sob o argumento de movimento reformista ou modernizando e, conforme afirma Paradela (1998, p. 81),

[...] como país dependente economicamente das grandes potências, o Brasil sempre buscou adequar sua máquina administrativa para a implementação das políticas impostas pelas nações hegemônicas e se utilizou do aparato estatal para implementar os modelos socioeconômicos relacionados a estes interesses.

E, assim, FHC marcou a era das mutações no Brasil em sintonia com o neoliberalismo, das quais a privatização de companhias estatais, a desregulamentação e a precarização do trabalho, além da "financeirização" da economia, teve impactos na mente dos políticos paranaenses, que em sua maioria, não mediram esforços para que os projetos de Lei que regulamentaria o uso sob concessão das rodovias fossem aprovados. A "concessão de rodovias teve forte componente de imposição por parte dos países centrais canalizadas por instituições como o FMI e o Banco Mundial" (FIGUEIREDO, 2003, p. 54).

Tanto no Congresso Nacional como na Assembleia Legislativa paranaense, o político que fosse contrário era considerado um atrasado, um obstruidor do avanço econômico que a onda de privatizar apregoava.

Em todos os oito anos de administração do governador Jaime Lerner, o que aconteceu foram tentativas, de privatizar empresas paranaenses para atingir os objetivos propostos no arcabouço de privatizações planejado no início de governo tanto do governo federal como estadual.

Neste período (de 1998 a 2002), uma das tentativas frustradas daquele governo foi a venda da Copel (Companhia Paranaense de Energia Elétrica). Esta que era a maior empresa estatal, foi motivo de intensos protestos e mobilizações populares, por fim acabou sendo inviabilizada pelos desgastes de inúmeras ações jurídicas e políticas, fazendo com que não tivesse nenhum lance quando colocada em leilão.

Porém, antes disso, já havia negociado o Banestado (único banco pertencente ao Estado), Telepar (empresa de telefonia) e 50\% da Sanepar (Companhia de saneamento) e a Ferroeste (Ferrovia Oeste do Paraná). Contudo, é provável que, a que mais sacrificaria o povo paranaense e demais pessoas que passam pelo Estado até hoje, foi a privatização das rodovias, que após a aprovação da Lei, foi implementado pelo governo paranaense a partir de 1997.

O governo do Paraná, sem base de comparação sobre os valores tarifários e com forte pregação ideológica, fez aprovar a norma, num ambiente político que parece cultuar um alto preço para se adentrar a modernidade. Quando a Lei Complementar $\mathrm{n}^{\circ}$ 76/1995, nas disposições preliminares do Art. $7^{\circ}$, inciso II, destaca sobre a modicidade dos preços e serviços, ou seja, a justa correlação entre os encargos da arrendatária e a retribuição dos usuários, dá para observar a subjetividade da disposição nesta pretensa modicidade como falácia, pois foi tragada pelas cláusulas do contrato durante a concessão. Mas muitos achavam que era o preço a se pagar pela "modernidade", tendo em vista alguns benefícios e a não existência de confrontação, supunha razoável aquela tarifa.

Mas o tempo possibilitou comparações e análises. O custo do pedágio nos trechos de rodovias do país, pelo governo federal em 2007, no governo de Luiz Inácio Lula da Silva, que concedeu em leilão, mostra a desproporção que se perpetrou contra a economia dos paranaenses. A partir dessas concessões federais, quando 
comparadas com as concessões que ocorreram no governo estadual, fica claro que, na época, o que prevaleceu não foi o interesse público em pagar o menor preço.

No programa Café com o Presidente, exibido no dia 15 de outubro de 2007, o assunto tratado foi o Leilão das rodovias federais. No tocante, o presidente Lula questionou a diferença significativa entre o valor do pedágio cobrado hoje, a partir da nova proposta de leilão, com o valor cobrado nas estradas leiloadas anteriormente. "Eu vou dar alguns exemplos", disse o presidente, "num trecho da Régis Bittencourt, nós colocamos como preço mínimo $R \$ 2,68$ e foi leiloado por $R \$ 1,35$. Na Fernão Dias, que nós colocamos um preço mínimo de $\mathrm{R} \$ 2,88$, foi leiloado por $\mathrm{R} \$ 0,99$. $E$ no trecho Curitiba-Florianópolis, nós colocamos um preço de $\mathrm{R} \$ 2,75$ e foi leiloado por R\$ 1,28" (CAFÉ COM PRESIDENTE, 2008).

Neste caso, não deixou de se apresentar oportunidade à iniciativa privada, mas o Estado cuidou de regular, contratando e atuando em favor da modicidade das tarifas. Se atualmente os paranaenses pagam seis vezes mais de pedágio nas estradas estaduais (próprias ou delegadas) em comparação com as rodovias federais, isso aponta para muitos equívocos nos contratos, ou melhor, nos acordos firmados com as concessionárias, com (des)amparo naquela Lei Complementar.

A lei de pedágio paranaense foi, portanto, construída neste ambiente de frouxidão política em relação aos cuidados com a missão do Estado em regular, fiscalizar e estabelecer condições de equilíbrio entre a remuneração das empresas e o interesse dos usuários. A lei definiu uma série de eventos, mas fora permissiva, quanto deveria exigir rigidez, em defesa do interesse coletivo.

\section{TARIFAS ELEVADAS}

Os efeitos da aprovação da Lei Complementar n 76/95 no Paraná foram tão proveitosos quanto o governo queria, mais abrangente que os paranaenses pudessem supor, e tão realista que custa muito no bolso dos usuários brasileiros, que pelo Estado trafegam.

Naquele ano de 1995, alguns deputados questionaram a viabilidade da concessão e passaram a criticar o formato de concessão adotado a partir de 1997. "Nós sempre afirmamos que esses contratos eram lesivos ao interesse público e que as tarifas cobradas eram extorsivas. Hoje, a partir do leilão realizado pelo governo federal, temos elementos ainda mais concretos para reafirmar essas convicções", comentou Péricles de Holleben Mello (MELLO, 2007), que continua:

O preço médio da tarifa nas estradas que foram pedagiadas a partir do leilão do governo federal é de $\mathrm{R} \$ 0,02$ (dois centavos) o quilômetro, ao passo que nas estradas pedagiadas do Paraná o preço é de $R \$ 0,12$ (doze centavos). Quem ia em 2007 de Curitiba a Florianópolis (300 quilômetros) vai pagar R\$ 5,14 , ao passo que hoje a tarifa para ir de Curitiba a Matinhos (100 quilômetros) é de $\mathrm{R} \$ 10,90$, e de Curitiba a Ponta Grossa (101 quilômetros), $\mathrm{R} \$ 11,70$.

Os arquétipos podem se repetir à exaustão, mas todos mostram a mesma realidade: o pedágio do Paraná é seis vezes mais caro que o pedágio federal. De tal forma, o problema maior está nas bases da política que instituiu o pedágio no Estado. Entre 1997 e 2007, várias ações foram movidas contra o pedágio, todas elas derrotadas e o motivo: a robustez da base formal dos contratos feitos. A planilha 
determinou o contrato e este estava robustamente amparado na Lei Complementar 76/1995.

As diferenças contratuais de concessão de uso e exploração das rodovias pedagiadas no Estado com as rodovias federais aparecem na nova proposta de leilão. O Governo Federal dispensou o pagamento de outorga, ou seja, as concessionárias vencedoras do leilão não estão obrigadas a contrapartidas como a manutenção de outras rodovias não licitadas. Além disso, diferente do que foi adotado no Paraná, onde as concessionárias têm até o final do contrato de 25 anos para concluir as obras previstas, o modelo de concessões do Governo Federal "prevê que a estrada seja totalmente recuperada e só então a partir disso será autorizado o início da cobrança" (BERNARDO, 2007). Mas pode-se indagar quanto isso vale? No Paraná, não se teve ainda condições de descobrir ${ }^{4}$. O resultado dessa diferença é que a taxa de retorno definida pelo leilão federal é inferior a $10 \%$ (acabou ficando em 8,95\%), enquanto no Paraná vai de $17 \%$ a $24 \%$. Comparando com os trechos federais que passam pelo Estado do Paraná outro estudo indica que "a concessão do Estado do Paraná apresentou uma Taxa de Retorno do Projeto Básico de 20,15\%" enquanto "do governo federal foi de 8,5\%" (PERBELINI, 2008, p. 196).

A alta lucratividade se explica também pelo modelo concorrencial. Para além da petrificação das cláusulas, os contratos feitos pelo governo paranaense com as concessionárias simulam uma concorrência, quando transparece que houve um acordo entre as empresas para dividir os lotes de concessão. Cada lote de rodovias foi ajustado para uma licitação, não houve concorrência global, fazendo com que houvesse suspeita de combinação entre as concorrentes.

A esta conclusão chegou uma comissão de técnicos liderada pelo então Deputado Péricles Mello, após verificar o formato e o tempo de cada edital. Naquele processo "as concessionárias simulam uma concorrência, quando na verdade houve um acordo entre as empreiteiras para dividir os lotes ofertados" (MELLO, 2007), o trabalho foi feito em 1998 e também mostrou, por exemplo, que uma placa de sinalização, grande, sobre a rodovia, que custaria no máximo $R \$ 10.000,00$, o usuário pagaria $\mathrm{R} \$ 35.000,00$, pois estava na planilha, este custo como sendo presumido. Demonstrava a necessidade do preço do pedágio para obter o tal equilíbrio econômico-financeiro em relação a todos os custos, inclusive sobre placas novas superfaturadas.

Este equilíbrio só existe para o lado do arrendatário, em nenhum momento da lei ou do contrato estabeleceu equação possível de ter o equilíbrio para o lado do usuário, quando as contas ficassem melhores para a empresa. Aliás, estas contas nunca estiveram, nem estarão similares com as do usuário, pois os custos tanto das melhorias como do financeiro (financiamento do investimento feito) foram superfaturados, de tal sorte que somente uma permanente tarifa alta manterá a remuneração destes cálculos. A pouca transparência - até acusação de imoralidade - no processo licitatório, em que possivelmente houve um pacto entre as arrendatárias, e a planilha que permitia altos pedágios dentro do pretenso e permanente equilíbrio econômico-financeiro, suportado na referida Lei e no contrato, trouxe grande vantagem às concessionárias.

O preceito do equilíbrio econômico-financeiro "além de servir de escudo protetor para as concessionárias, age como elemento de atração à entrada no negócio

\footnotetext{
${ }^{4}$ Segundo o Ministério Público Federal, há pelo menos 13 atos "secretos" que permitiram modificar as condições originais de concessão desde o início do programa de pedagiamento (SENGE-PR, 2014, p. 29).
} 
de concessão, por garantir as regras iniciais de lucratividade" (FIGUEIREDO, 2003, p. 53).

Um estudo comparativo entre o modelo adotado pelo Estado do Paraná no período de 1995-2002 e do governo federal em 2007, feito pelos economistas Alessandro de Melo Perbelini e Maria da Piedade Araújo, conclui que "o critério estabelecido pelo governo paranaense pode estar contrariando o princípio da modicidade das tarifas" e as ações decorrentes do modelo paranaense usado "conduziram a um prejuízo aos usuários da rodovia" (PERBELINI; ARAÚJO, 2008, p. 2006 e 2007).

Em 2007, o segmento de administração e concessão de rodovias registrou a maior rentabilidade do país. O estudo foi elaborado pela agência classificadora de risco de crédito Austin Rating. "Com uma rentabilidade de 33,9\%, as concessionárias de pedágio ficaram à frente de setores historicamente fortes da economia brasileira como o financeiro, o de telecomunicações, a siderurgia e o segmento de bebidas e fumo" (Folha de S. Paulo, 2008). Poucos imaginavam que algumas empresas pudessem suplantar os altos e reiterados ganhos do setor financeiro (bancos) brasileiros, mas as concessionárias do Paraná conseguiram este intento.

Desde a implantação do pedágio, a arrecadação tarifária foi aumentando ano a ano. Em 1999 foi de 165 mil reais, em 2012 passou a ser de 1 bilhão e 641 milhões. A organização de dados disponíveis no gráfico, contribui para dar uma ideia desta evolução.

GRAFICO 1 - Arrecadação do pedágio paranaense entre os anos 1999 e 2014

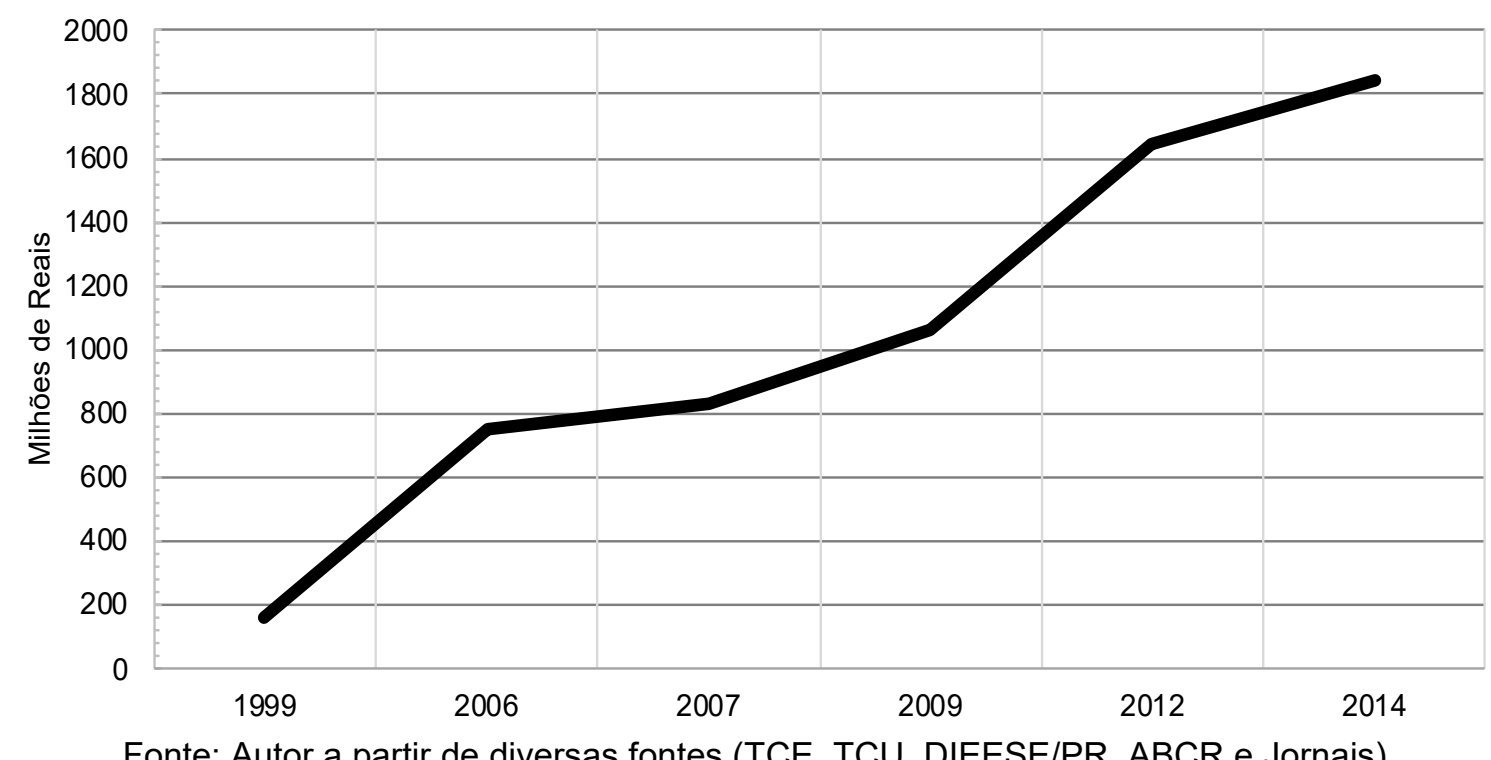

Fonte: Autor a partir de diversas fontes (TCE, TCU, DIEESE/PR, ABCR e Jornais).

Em relação ao lucro líquido temos dados de 2013, que foi de 424,2 milhões de reais e de 2014, que foi de 437,8 milhões (GAZETA DO POVO, 2015). A alta arrecadação e o baixo investimento explicam a lucratividade. "A alta rentabilidade do setor foi causada entre alguns fatores pelo alto preço do quilômetro rodado no país um dos maiores do mundo - e pela ausência de grandes investimentos justificados pelo fato das rodovias privatizadas estarem em condições relativamente razoáveis de uso" (Folha de S. Paulo, 2008, grifo nosso). 
Cabe aqui a reflexão de Mário Figueiredo (2003, p. 54) "de que o comportamento dos empresários é orientado no sentido de maximizar os lucros, enquanto que o dos legisladores é pautado com vistas a maximizar o apoio político". Acrescento: no mesmo tema, no mesmo período, porém em sentido contrário ao interesse público, ou seja, de coadunar bom serviços viários com modicidade tarifária. Aliás, este "era um dos objetivos das concessões" (FIGUEIREDO, 2003, p. 54).

\section{SEGURANÇA JURÍDICA: todo poder ao contrato}

Para demonstrar a segurança jurídica proporcionada pela lei e pelos contratos, basta resumir aqui o conjunto de inciativas que os testaram. Desde a implantação do pedágio em 1997 até 2015 foram ajuizadas mais de 50 ações. Algumas contra a cobrança do pedágio e outras apenas contra a majoração tarifária.

Foram ações movidas por populares, associação de caminhoneiros, partidos políticos, Ministério Público e até pelo próprio governo. Entre 2003 e 2010 o governo do Estado do Paraná ajuizou mais de 30 ações na esfera federal. Até 2006 várias ações também foram protocoladas junto à Justiça Estadual; contudo, naquele ano o Superior Tribunal de Justiça definiu que esta questão seria apenas de competência da Justiça Federal.

Houve algumas ações que conseguiram liminares e os preços das tarifas, temporariamente, não sofreram majoração. Este foi o patamar de maior sucesso destas tentativas, pois de resto, todas as liminares e decisões em sentença foram favoráveis às concessionárias.

Em 2013, o Tribunal de Contas do Estado do Paraná (TCE-PR), através de uma auditoria nas planilhas, apurou que as tarifas estavam desiquilibradas em desfavor aos usuários. Apesar disso nenhuma mudança tarifária a menor.

Como vimos anteriormente, a lei paranaense de concessão foi construída para ser permissiva, deixou diversas lacunas que por sua vez remetia ao contrato todas as condições de gestão.

Não havia marco regulatório e nem agência de controle, nos moldes dos países centrais, com vasta práxis ${ }^{5}$ neste assunto, associado ainda às poucas amarras legais, coube as empresas cuidarem de colocar toda força nas letras do contrato com o Estado. Toda regulação que ocorreu a posteriori, ou mesmo os questionamentos administrativos e jurídicos mostrou quão fragilizado ficou o usuário perante a força das empresas concessionárias.

Outros fatos decorrentes de as concessões terem acontecido antes de se ter o marco regulatório completamente definido é sua dependência às cláusulas contratuais que fragilizam e põem à mostra o caráter antitético do processo regulatório, onde os interesses públicos se chocam com os interesses de lucro de empresário das concessionárias (FIGUEIREDO, 2003, p. 54).

\footnotetext{
${ }^{5}$ Aqui o termo é usado para referir-se ao processo de colocar em prática uma concepção (ou teoria) e ao aplicar na prática, reavaliar e reconsiderar aspectos, chegando a uma nova concepção que implica em ajustes daquelas práticas, num devir prático sintético. Em 1877, em Illinois (EUA), iniciou-se a prática de regulação de preços aos possuidores de poder econômico na exploração do consumo. Neste caso o Estado se apresenta para impor limitações a esta exploração (FIGUEIREDO, 2003, p. 44). Mais tarde, experimentando outras concessões, buscou-se, além de limitar os preços, a especificar a qualidade e a segurança dos serviços e produtos.
} 


\section{a) Equilíbrio econômico - financeiro.}

A cláusula de equilíbrio econômico-financeiro estabelecera a margem de remuneração constante para as empresas. "Há que ser ressaltado que a cláusula referente ao equilíbrio econômico-financeiro da concessionária não é uma liberalidade do Governo do Paraná" (FIGUEIREDO, 2003, p. 52) pois, a partir da assinatura do contrato, passará ser direito da empresa a percepção remuneratória estabelecida a priori, que sempre viabiliza sua alta lucratividade, por antecipação, visto que, em havendo desequilíbrio ao percentual de vantagem, diminui serviços e suportes. $O$ contrário não está estabelecido, pois na lógica da filosofia econômico-política, a lucratividade garantida, é o retorno pelo risco assumido pela empresa.

Cabe salientar que neste interregno de tempo, após a saída do governo Jaime Lerner, tivemos mais dois outros governadores que propuseram acabar ou estabelecer baixas nas tarifas do pedágio. Houve tentativas pela via administrativa, com a atuação do Departamento de Estrada e Rodagem; pela via política, atuando diretamente com a associação que reúne as empresas concessionárias e, como vimos, pela via judicial, com o apoio da Procuradoria do Estado, porém, nenhum deles tiveram sucesso.

Em um estudo apresentado em 2011, Delci Grapegia Dal Vesco e outros, analisam as tentativas de rebaixamento do pedágio, até mesmo com a diminuição dos serviços e compromissos das concessionárias. Discorre sobre o tema com levantamento estatísticos e utiliza a teoria dos contratos. Então chega a conclusão que nenhuma investida sobre o contrato afetou o desempenho das empresas concessionárias:

[...] pelo pressuposto teórico que define risco como o potencial de eventos ou tendências continuadas causarem perdas ou flutuações em receitas futuras não foi observado estatisticamente. Esse fato foi analisado com o desenho contratual e justifica-se devido ao formato do contrato de concessão prever o equilíbrio econômico e financeiro, ou seja, reduz tarifas reduz investimentos, logo dadas as características dos agentes e das transações manteve-se a estrutura de governança. [...] foi possível concluir a pesquisa identificando que os agentes são movidos pelas características de oportunismo, contudo a estrutura contratual foi mantida pois os contratos foram elaborados com cláusulas que permitiram o equilíbrio econômico e financeiro contratual e assim não foi possível inferir que afetou o desempenho (DAL VESCO, 2011, p. 14).

\section{b) Obrigações não cumpridas}

No início de 2012, o Tribunal de Contas da União (TCU) aprova um relatório de auditoria, determinando ao Estado do Paraná que reveja a questão do equilíbrio financeiro das concessionárias e que estas fizessem os investimentos considerando a necessidade pública e em função das taxas de rentabilidade. O relatório conclui que às alterações contratuais do Estado com as concessionárias apresentam ausência de critérios técnicos de engenharia na definição dos remanejamentos de obras e, ao que parece, foram promovidas meras alterações nos números que compõem o fluxo de caixa, a fim de transparecer um equilíbrio financeiro fictício e desconectado das necessidades dos trechos rodoviários concedidos (TCU, 2012, p. 15, grifo nosso).

Decorre que, para que esta ficção tornasse real outra alteração contratual, criaram-se critérios de medição apenas quantitativa dos insumos quando da medição dos investimentos nas rodovias. Com isso, mais dificultosa ficou a fiscalização e o 
"menor incentivo ao uso de materiais duráveis nas obras" pois ao contrário seria que quanto mais bem executados com insumos de qualidade os serviços iniciais, menores seriam os custos de manutenção das vias. Porém, "com o uso do critério de insumos para medição, mais baixa a qualidade dos materiais empregados nas rodovias, mais intervenções precisarão ser executadas, mais insumos aplicados e, consequentemente, maiores os ganhos do concessionário (TCU, 2012, p. 15).

Com gastos apresentados nas planilhas em que o quantitativo de pobres insumos que garantiam a lucratividade, as empresas aceitaram a redução de investimento em obras conforme planejamento contatual inicial - pois estavam desobrigadas. Segundo este documento, o DER-PR informa que a "exclusão de obras que não foram razoáveis e visaram a um teórico equilíbrio econômico-financeiro desprovido de suporte técnico" (TCU, 2012, p. 20).

Consequente, a esta decisão do TCU, o TCE-PR auditou os contratos e pediu "reintrodução na concessão de investimentos equivalentes a R\$347,609 milhões a valores de dezembro de 2012" e a redução das tarifas em 31,90\% (SENGE-PR, 2014, p. 28). O Ministério Público Federal tratou esta exclusão de obras num exemplo que aconteceu numa "ata de uma reunião de 2005 entre o Paraná e a Ecocataratas, que trocaram todos os investimentos de duplicação por uma redução de $30 \%$ na tarifa do pedágio" (SENGE-PR, 2014, p. 29).

Ao analisar esta sequência de fatos, inferimos que o equilíbrio econômico financeiro foi um fator central na lucratividade planejada das concessionárias, que a lei garantiu nos termos contratuais. Para uma redução da tarifa no ano de 2005, excluiu-se obras que nunca mais foram retomadas, porém ao longo do tempo o investimento daquelas obras foram parar nas planilhas como insumos investidos, a fim de devolver a condição de lucratividade que as obras dariam desde o início da concessão.

Com resultado aos aditivos contratuais sem suporte técnico - proposital, como se infere - associado a equilíbrios fictícios dos investimos em insumos de baixa qualidade, necessitando de grande quantidade, resultou na prática, da exclusão de obras segundo "as necessidades públicas" (TCU, 2012, p. 23), como duplicações, trincheiras, acessos e outros benefícios prometidos no início da concessão.

\section{CONSIDERAÇÕES FINAIS}

A alta lucratividade do pedágio paranaense, identificada a partir deste estudo, só foi possível, por não haver nenhum recuo em favor aos usuários, por conta de uma legislação aprovada no final de 1995, que consagrou o valor das planilhas e do equilíbrio econômico-financeiro em favor das empresas concessionárias, por serem recepcionadas nas cláusulas contratuais petrificadas. Esta Legislação foi aprovada pela maioria dos deputados, dentro de um contexto econômico neoliberal.

A norma aprovada, para além da substituição do Estado no controle das rodovias, afastou a presença estatal do planejamento, da fiscalização e da função de mediador do interesse público. Uma das conclusões que podemos inferir neste breve estudo é que a pretensa racionalidade do capital forçou a irracionalidade do Estado.

Parte desta análise, em um hiato temporal de dez anos, entre a implantação pelo Estado do Paraná de seu modelo de privatização de rodovias, em 1997, e a implantação pelo governo federal, em 2007 em seu formato diferenciado de leilão, este se mostrou em menor apelo liberalizante, percebidos, comparativamente, pela 
menor lucratividade por parte das empresas e pelo formato de contratação, em que a modicidade dos preços prevalecem, voltados para o interesse geral.

Naquele dia 21 de dezembro de 1995, quando se votava uma lei, na Assembleia Legislativa do Paraná, considerada moderna e avançada, que previa a necessária segurança e incentivo para as privatizações, apenas três vozes - votos em nome de suas bancadas, se manifestaram contra aquele formato. Pelo contexto da hegemonia do pensamento neoliberal, pareciam estes votos, que estavam em descompasso com o momento. Mas o tempo e as comparações indicaram o contrário.

Passados mais de 20 anos, percebe-se que a Lei está sendo aplicada e que os usuários continuam insatisfeitos com os serviços prestados pelas concessionárias em relação às tarifas pagas. Lembrando que, em breve, o contrato será extinto, restando à sociedade mobilizar-se, com base em mais informações e confrontações com outros modelos, e maior participação, para alteração dos próximos modelos de leilão e dos termos contratuais.

Este tema fica proposto para outra discussão, considerando que o recorte temporal do presente estudo, resta ainda um tempo para aprofundar a análise e inclusive dar base para decisão sobre a oportunidade e conveniência de novas concessões.

\section{REFERÊNCIAS}

ANTUNES, Ricardo. A desertificação neoliberal no Brasil (Collor, FHC e Lula). Campinas-SP: Autores Associados, 2004.

ARIĖS, Philippe. O tempo da história. Rio de Janeiro: Francisco Alves Editora, 1989.

ASSEMBLÉIA LEGISLATIVA DO PARANÁ. Projeto de Lei Complementar no. 20/1995. Dispõe sobre o regime de concessão e permissão da prestação de serviços públicos no Estado do paraná (pedágio). Deputado Neivo Beraldin, 23 de fevereiro de 1995.

ASSEMBLÉIA LEGISLATIVA DO PARANÁ. Ata do dia 14/12/1995. Pág. 11.

ASSEMBLÉIA LEGISLATIVA DO PARANÁ. Ata do dia 19/12/1995. Págs. 12-25.

ASSEMBLÉIA LEGISLATIVA DO PARANÁ. Ata do dia 20/12/1995. Págs. 02-05.

ASSEMBLÉIA LEGISLATIVA DO PARANÁ. Ata do dia 21/12/1995. Págs. 11- 18.

BERNARDO, Paulo. Entrevista com o Ministro Paulo Bernardo. NBR. Novembro de 2007.

BRASIL. Câmara dos Deputados. Manual de Redação. Brasília: Câmara dos Deputados, Coordenação de Publicações, 2004, 420 p.

CAFÉ COM O PRESIDENTE. Entrevista com Lula sobre o leilão das rodovias. Agência Brasil. Capturada em 28 de fevereiro de 2008, às 22h23min. 
CONGRESSO EM FOCO (Revista). Pedágio no Brasil está entre os mais caros do mundo. Em http://congressoemfoco.uol.com.br/noticias/pedagio-no-pais-e-maiscaro-que-media-internacional/. Acessado em 12 de novembro de 2015.

DAL VESCO, D. et al. A mudança política no governo estadual do Paraná versus risco dos contratos de concessão rodoviária. ANPAD, Rio de Janeiro, 2011.

FENASDETRAN. Paraná tem o pedágio mais caro do mundo. Em http://fenasdetran.com/noticia/parana-tem-o-pedagio-mais-caro-do-mundo. Acessado em 12 de novembro de 2015.

FIGUEIREDO, Mário João. A concessão de rodovias paranaenses: uma análise à luz das teorias da regulação. In: II ECOPAR, 2, 2003, Maringá, Anais... Maringá: UEMUEL-UEPG-UNIOESTE-IPARDES, 2003, p. 43-55.

FOLHA DE SÃO PAULO. Pedágio foi o negócio mais lucrativo de 2007. Dia 09 de março de 2008.

GAZETA DO POVO. Quanto cada concessionária de pedágio lucrou em 2014 ? Dia 05 de maio de 2015.

KARAM R. \& SHIMA, W. T. A concessão de rodovias paranaenses: um serviço público sob a ótica do lucro. Revista Paranaense de Desenvolvimento, Curitiba, n.113, p.103-127, jul./dez. 2007.

LEME, Alessandro André. Neoliberalismo, globalização e reformas do Estado: reflexões acerca da temática. In: Revista Barbarói, Santa Cruz do Sul, n. 32, p. 114138, jan./jul. 2010.

MELLO, PÉRICLES DE HOLLEBEN. Opinião. O Estado do Paraná. Dia 24 de outubro de 2007.

NEGRÃO, João José de Oliveira. O governo FHC e o neoliberalismo. In: Revista Lutas Sociais, PUC-SP, São Paulo, Vol. 1, p. 103-112, nov. 1996.

PARANÁ. Lei Complementar n 76 de 21 de dezembro de 1995. Dispõe sobre o regime de concessão e permissão da prestação de serviços públicos no Estado do Paraná. Diário Oficial do Estado n 4660, de 21 de dezembro de 1995.

PARANÁ ONLINE TRIBUNA. Paranaenses não concordam com o preço dos pedágios. Publicado em 12 de outubro de 2013. Em http://www.paranaonline.com.br/editoria/economia/news/777397/. Acessado em 12 de novembro de 2015.

PARADELA, Célia Lima. Desestatização da Rede Ferroviária Federal S/A: impactos sobre os recursos humanos da administração geral. Dissertação de Mestrado, apresentado a Escola Brasileira de Administração Pública, FGV, 1998.

PERBELINI, Alessandro de Melo; ARAÚJO, Maria da Piedade. Concessões de rodovias do Paraná: uma análise comparativa com o modelo federal de 2007 . In: 
Revista Paranaense de Desenvolvimento, Curitiba, n. 114, p. 179-210, jan./jul. 2008.

SENGE-PR (Sindicato dos Engenheiros do Estado do Paraná). Representação junto ao Ministério dos Transportes: contra o Estado do Paraná. Curitiba, 2014.

TCU (Tribunal de Contas da União). Relatório. Acórdão no. 346. Plenário, Brasília, 2012. 
Irineu Mario Colombo 